\title{
Calcification of coronary arteries and abdominal aorta in relation to traditional and novel risk factors of atherosclerosis in hemodialysis patients
}

\author{
Przemysław Pencak', Beata Czerwieńska², Rafał Ficek², Katarzyna Wyskida², Agata Kujawa-Szewieczek², \\ Magdalena Olszanecka-Glinianowicz ${ }^{3}$, Andrzej Więcek ${ }^{2}$ and Jerzy Chudek C., $^{*}$
}

\begin{abstract}
Background: Process of accelerated atherosclerosis specific for uremia increases cardiovascular risk in patients with chronic kidney disease (CKD) and may be influenced by the different structure of arteries. The study assesses the influence of traditional and novel risk factors on calcification of coronary arteries (CAC) and abdominal aorta (AAC) in hemodialysis patients (HD).

Methods: CAC and AAC were assessed by CT in 104 prevalent adult HD and 14 apparently healthy subjects with normal kidney function (control group). Mineral metabolism parameters, plasma levels of FGF-23, MGP, osteoprotegerin, osteopontin, fetuin-A, CRP, IL-6 and TNF-a were measured.

Results: CAC and AAC (calcification score $\geq 1$ ) were found in 76 (73.1\%) and 83 (79.8\%) HD respectively, more frequent than in the control group. In $7 \mathrm{HD}$ with $A A C$ no CAC were detected. The frequency and severity of calcifications increased with age. Both CAC and AAC were more frequently detected in diabetics $(O R=17.37$ and 13.00, respectively). CAC score was significantly greater in males. CAC and AAC scores were correlated significantly with pack-years of smoking and plasma osteoprotegrin levels. However the independent contribution of plasma osteoprotegerin levels was not confirmed in multiple regression analysis. Age $(\mathrm{OR}=1.13)$ and hemodialysis vintage $(O R=1.14)$ were the independent risk factor favoring the occurrence of $C A C$; while age $(O R=1.20)$ was the only predictor of AAC occurrence in HD.
\end{abstract}

Conclusions: 1. AAC precedes the occurrence of CAC in HD patients. 2. The exposition to uremic milieu and systemic chronic microinflammation has more deteriorative effect on the CAC than the AAC.

Keywords: Atherosclerosis, Risk factors, Hemodialysis

\section{Background}

Cardiovascular diseases remain the leading cause of morbidity and mortality, regardless of the significant progress of revascularization procedures and their accessibility, in patients with chronic kidney disease (CKD). In CKD patients, especially in those on dialysis therapy, the risk of cardiovascular death is particularly high, 1020 times greater than in the general population [Foley et al. [1]]. At least in part the increased risk is related to

\footnotetext{
*Correspondence: chj@poczta.fm

${ }^{2}$ Department of Nephrology, Endocrinology and Metabolic Diseases, Medical University of Silesia, Katowice, Poland

${ }^{4}$ Pathophysiology Unit, Department of Pathophysiology, Medical University of Silesia, Katowice, Poland

Full list of author information is available at the end of the article
}

accelerated development of atherosclerosis, that cannot be only attributed to the presence of the traditional risk factors such as age, sex, smoking, obesity, dyslipidemia, hypertension and diabetes. In 1974, Lindner et al. [2] described the phenomenon of the accelerated atherosclerosis in dialysis patients, that has not been fully explained for nearly forty years. The development of accelerated atherosclerosis and typical for CKD calcification of tunica media, labeled as Monckeberg's sclerosis is associated with transformation of vascular smooth muscle cells (VSMCs) into osteoblast-like cells, able to synthesize bone matrix protein-2 (BMP-2), matrix Gla protein (MGP) and osteopontin [3]. Osteoblasts in vascular wall may also arise from mesenchymal cells - 
pericytes. It is believed that about $10-30 \%$ pericytes can be converted into bone cells [4].

The process of vascular calcification of systemic arteries probably differs in muscular and elastic vessels. High number of VSMCs in the tunica media of muscle arteries seems to predispose, whereas high content of elastic fibers in elastic large arteries may protect against Monckeberg's calcifications development. It should be stress, that degradation of elastic fibers by matrix metalloproteinases with generation of soluble elastin peptides may stimulate VSMCs transformation into osteoblastlike cells [5]. This process of vascular calcification is similar to the process of bone formation.

Recent evidence suggests that the interaction of traditional (i.e., Framingham: age, lifestyle, diabetes, hypertension, dyslipidemia) and uremia-related, so could novel (e.g. hyperphosphataemia, high calcium $x$ phosphorus product, hyperparathyroidism, oxidative stress, systemic inflammation, protein-energy wasting, asymmetric dimethylarginine, P-cresol, fetuin A) cardiovascular risk factors contribute in excessive and accelerated vascular calcifications in CKD patients [6]. In elderly CKD patients, traditional cardiovascular risk factors probable participate more than the novel ones in the development of vascular calcifications. Shlipak et al. showed that traditional cardiovascular risk factors had larger associations with cardiovascular mortality than novel risk factors in elderly CKD (non-dialysis) persons [7]. However, whether their role in the development of calcification in muscular and elastic vessels is similar is not yet known.

Therefore the aim of the present study was to assesses the influence of traditional and novel risk factors on calcification of coronary arteries and abdominal aorta in hemodialysis patients.

\section{Methods}

One-hundred-four stable, prevalent hemodialysis patients (HD; 56 males and 48 females) from single HD unite (recruited from 2009 to 2011) and 14 apparently healthy subjects with normal kidney function (control group) were included into the study. Patients on HD therapy for less than 3 months, any acute illnesses within a month, cancers, liver cirrhosis and treated with cinacalcet were excluded from the study. Study protocol was approved by the Bioethics Committee of Medical University of Silesia (KNW-6501-37/I/08). All patients gave informed consent for participation in the study.

All patients from the HD group were on hemodialysis 3 times per week for 4-5 hours sessions. Bicarbonatebuffered dialysate fluid containing $2-3 \mathrm{mmol} / \mathrm{L}$ potassium, $1,25 \mathrm{mmol} / \mathrm{L}$ calcium, $0.75 \mathrm{mmol} / \mathrm{L}$ of magnesium and low-flux polysulfone or cuprofane dialysis membranes were used in all patients. HD patients characteristics including CKD causes, duration of hemodialysis therapy, $\mathrm{Kt} / \mathrm{V}$ and comorbidities are given in Table 1.

The control group consisted of 14 apparently healthy adults in similar age - range from 23 to 85 years (6 males and 8 females) with normal kidney function (eGFR-MDRD $>90 \mathrm{ml} / \mathrm{min} / 1.73 \mathrm{~m}^{2}$ ) and without significant albuminuria.

The study protocol assumed anthropometric measurements, blood sampling performed during the morning before computed tomography (CT) scanning after overnight fast. In addition monthly, routinely measured parameters (complete blood count, serum concentrations of albumin, urea, calcium, phosphorous, intact parathyroid hormone, sodium, potassium, total, LDL and HDL cholesterol and triglycerides) were obtained before mid-week HD session. Plasma samples for estimation of CRP, IL-6, TNF- $\alpha$, fetuin-A, osteoprotegerin, osteopontin, osteokalcin, MGP, intact fibroblast growth factor 23 (FGF-23) and $25(\mathrm{OH}) \mathrm{D}_{3}$ were stored frozen at $-70^{\circ} \mathrm{C}$ till assessment.

\section{Measurement calcification score with multislice spiral computed tomography (MSCT)}

Measurement of coronary arteries $(\mathrm{CAC})$ and abdominal aorta (AAC) calcifications was performed with 64-row CT scanner Aquilion 64 (Toshiba Medical Systems Corporation) equipped with an integrated ECG monitor and appropriate software for testing and evaluation of calcium Agatston score.

Scanning was done in sequential $3 \mathrm{~mm}$ thick layers (for aorta starting scanning $3 \mathrm{~cm}$ proximal to the bifurcation of the aorta). After the test, the images were transferred to a dedicated workstation VITREA 2 (Vital Images, Inc.) equipped with program to calculate Agatston score. Calculations were done automatically after determination by the radiologist the calcification in the arterial wall in appropriate scans. The results were readout of the workstation monitor.

\section{Laboratory analyses}

Routine laboratory measurements were performed in hospital laboratory (Synchron Cx-9, Beckman Coulter Inc., Fullerton, CA, U.S.). Serum high sensitivity CRP was measured by nephelometry (Siemens Healthcare Diagnostics, Deerfield, IL, U.S.) with a lower limit of sensitivity of $0.2 \mathrm{mg} / \mathrm{l}$.

Plasma concentrations of IL-6 (R\&D System, Minnesota, MN, U.S.), TNF- $\alpha$ (R\&D System, Minnesota, MN, U. S.), MGP (Biomedica, Wien, Austria), fetuin-A and osteopontin (DRG, Mountainside, NJ, U.S.), osteoprotegerin (Biovendor, Modřice, Czech Republic), osteocalcin (Quidel, San Diego, CA, U.S.), 25-OH-D 3 (Immundiagnostik, Bensheim, Austria), and FGF-23 
Table 1 Demographic and clinical characteristics of study participants (mean \& 95\% Cl)

\begin{tabular}{|c|c|c|c|}
\hline & $\begin{array}{l}\text { Hemodialysis group } \\
\qquad(\mathrm{N}=104)\end{array}$ & $\begin{array}{c}\text { Control group } \\
(N=14)\end{array}$ & $\begin{array}{c}\text { Statistical } \\
\text { significance }\end{array}$ \\
\hline Age (years) & $53.6(50.3-56.9)$ & $54.6(45.1-64.1)$ & 0.93 \\
\hline Gender (male/female) & $56 / 48$ & $6 / 8$ & 0.63 \\
\hline Body mass index $\left(\mathrm{kg} / \mathrm{m}^{2}\right)$ & $24.9(23.3-26.6)$ & $24.7(23.9-25.6)$ & 0.82 \\
\hline Obesity (BMl $\geq 30$ kg/m²) (n/\%) & $11 / 10.6$ & 0 & 0.43 \\
\hline Smokers (n/\%) & $62 / 59.6$ & $1 / 7.1$ & $<0.001$ \\
\hline Smoking burden (pack-years) & $15(12-18)$ & & \\
\hline Family burden (n/\%) & $32 / 30.8$ & NA. & \\
\hline \multicolumn{4}{|l|}{ Primary cause of CKD ( $n / \%)$} \\
\hline Diabetes & $11 / 10.6$ & & \\
\hline Hypertension & $4 / 3.8$ & & \\
\hline Nephrolithiasis & $3 / 2.9$ & & \\
\hline Autosomal Dominant Polycystic Kidney Disease (ADPKD) & $6 / 5.8$ & & \\
\hline Ischemic nephropathy & $5 / 4.8$ & & \\
\hline Glomerulonephritis & $50 / 48.1$ & & \\
\hline Urinary tract infection & $6 / 5.8$ & & \\
\hline Amyloidosis & $3 / 2.9$ & & \\
\hline Other or unknown & $16 / 15.4$ & & \\
\hline Time on dialysis (months) & $45(33-54)$ & & \\
\hline Kt/N (per HD session) & $1.29(1.25-1.34)$ & & \\
\hline \multicolumn{4}{|l|}{ Co-morbidity (\%) } \\
\hline Hypertension & $87 / 84.5$ & 0 & \\
\hline Diabetes & $19 / 18.3$ & 0 & \\
\hline Coronary artery disease & $35 / 33.7$ & 0 & \\
\hline Stroke & $9 / 8.7$ & 0 & \\
\hline Past kidney transplantation & $18 / 17.3$ & - & \\
\hline \multicolumn{4}{|l|}{ Pharmacotherapy (n/\%) } \\
\hline Antihypertensive & $79 / 76.0$ & & \\
\hline No of antihypertensive drugs (n) & $2.0(1.7-2.2)$ & & \\
\hline Oral anti-diabetic* & $5 / 26.3$ & & \\
\hline Insulin* & $14 / 73.7$ & & \\
\hline Antiplatelet & $52 / 50.0$ & & \\
\hline Oral anticoagulant & $9 / 8.7$ & & \\
\hline Statins & $18 / 17.3$ & & \\
\hline Fibrates & 0 & & \\
\hline Oral phosphorous binders & $102 / 98.1$ & & \\
\hline Carbonate calcium dose (g/day) & $3.3(2.9-3.7)$ & & \\
\hline Sevelamer hydrochloride (g/day) & 0 & & \\
\hline Alfacalcidol & $82 / 78.8$ & & \\
\hline Alfacalcidol dose ( $\mu \mathrm{g} /$ week) & $2.5(1.1-3.8)$ & & \\
\hline
\end{tabular}

* for patients with diabetes.

NA. - not available. 
(Immuntopics, San Clemente, CA, U.S.) were determined by ELISA.

\section{Data analysis}

Arterial hypertension was defined as the predialysis blood pressure values $\geq 140 / 90 \mathrm{mmHg}$ or antihypertensive medication. Dyslipidemia was defined as the concentration of total cholesterol $\geq 5.0 \mathrm{mmol} / \mathrm{L}$ or LDL-cholesterol $\geq 3.0 \mathrm{mmol} / \mathrm{L}$ or low HDL-cholesterol $(<1.0 \mathrm{mmol} / \mathrm{L}$ for men and $<1.2 \mathrm{mmol} / \mathrm{L}$ for women) or triglycerides $\geq 1.7 \mathrm{mmol} / \mathrm{L}$ or lipid lowering therapy. Obesity was diagnosed according WHO criteria.

On the basis of CAC Agatston score we classified calcifications in patients according to Rumberger et al. criteria as: mild (1-10), moderate (11-100), large (101$400)$ and massive (> 400) [8]. The severity of AAC were scored according own classification, based on an exponential scale: mild (1-100), moderate (101-1000) and large (> 1000).

HD patients were divided into 3 subgroups: with calcification in both locations (CAC and AAC), with isolated aorta calcifications (AAC only) and without calcifications.

\section{Statistical analysis}

Statistical analysis was performed with STATISTICA 10.0 PL Stat Soft Corporation software (www.statsoft. com). Results are given as mean values with $95 \%$ confidence intervals $(95 \% \mathrm{CI})$. For comparison of groups, we used the $x^{2}$ test and $x^{2}$ test for trend (qualitative variables) and ANOVA, followed by Tukey's test or U-Mann-Whitney test, as appropriate (quantitative variables). Correlation coefficient was calculated according to Spearman. Univariate and multivariate backward stepwise logistic regression analysis were performed including factors potentially favoring or preventing the calcification development, including age, hemodialysis vintage, gender, hypertension, diabetes, current smoking or pack-years exposition, levels of phosphorous, calcium, $\mathrm{PTH}, 25(\mathrm{OH}) \mathrm{D}_{3}$, osteoprotegerin, MGP, CRP, IL-6, TNF- $\alpha$. All variables were tested for the presence of multi co-linearity, which was assessed with the variance inflation factor and the conditional index. $\mathrm{p}<0.05$ was considered as statistically significant.

\section{Results}

Characteristics of study groups is given in Table 1. CAC (calcification score $\geq 1$ ) were found in $76 \mathrm{HD}$ patients (73.1\%), and 5 in the control group (35.7\%) - p <0.01 (with Yates correction). Among HD patients 6 had mild (5.8\%), 10 moderate (9.6\%), 12 large (13.5\%) and 48 massive (46.1\%) CAC.

Within the abdominal aorta calcifications were detected in 83 HD patients (79.8\%) and 6 in the control group (42.9\%) - p $<0.01$ (with Yates correction). Among HD patients mild AAC were found in 7 subjects (6.7\%), moderate in 19 (18.3\%) and severe in 57 (54.8\%). The frequency of calcifications increased with age (Figure 1).

The severity of CAC and AAC was significantly greater in $\mathrm{HD}$ patients than in the control group (Table 2). Among HD patients, AAC was detected from age of 25 years, while CAC from age of 28 years. CAC score (CACS) was significantly higher in males than in females [1196 (720-1672) vs. 644 (324-964), $\mathrm{p}=0.001$ ], while AAC score was similar $[2971(1968-3974)$ vs. 2544 (1558-3530), $\mathrm{p}=0.49$; respectively]. Calcifications in both locations were detected in each patient diagnosed with diabetes $[\mathrm{OR}=17.37$ (1.01-298.56), $\mathrm{p}=0.049$ and $13.00(0.75-224.58, \mathrm{p}=0.08)$ for $\mathrm{CAC}$ and AAC respectively], and were more severe than in not diabetics [1464 (704-2224) vs. 825 (502-1147), $\mathrm{p}=0.001$ and 4987 (2861-7112) vs. 2279 (1591-2967), p<0.001; respectively]. Diabetic patients were significantly older [64 $(58-70)$ vs. $51(48-59)$ years, $\mathrm{p}=0.003$ ] but not HD vintage was similar. There was no association between occurrence of calcifications and smoking or dyslipidemia. Among smokers there were correlations between pack-years and CAC as well as AAC scores $(R=0.37$, $\mathrm{p}=0.002$ and $\mathrm{R}=0.36, \mathrm{p}=0.002$; respectively).

All but two HD patients, with CAC detected, had AAC. However, in 7 patients with AAC no CAC was detected (kappa coefficient 0.798, 95\% CI 0.708-0.870). The correlation between $\mathrm{CAC}$ and $\mathrm{AAC}$ scores was slightly stronger for control group $(R=0.70, p<0.001$ in $\mathrm{HD}$ and $\mathrm{R}=0.78, \mathrm{p}=0.001$ in controls).

\section{Characteristics of patients with calcifications}

Patients with detectable both CAC and AAC were 29 years older and had longer history of HD therapy than those without calcifications (Table 3). This group included all diabetics, all but 2 with CAC, the highest percentage of patients with hypertension and low PTH

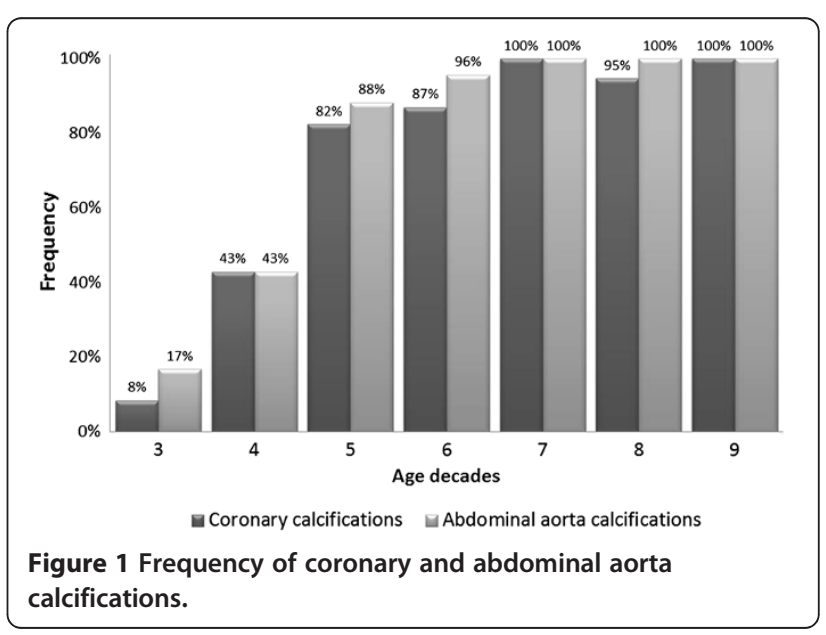


Table 2 Calcification scores and biochemical characteristics of study groups (mean \& 95\% Cl)

\begin{tabular}{|c|c|c|c|}
\hline & $\begin{array}{l}\text { Hemodialysis group } \\
(\mathrm{N}=104)\end{array}$ & $\begin{array}{c}\text { Control group } \\
(\mathrm{N}=14)\end{array}$ & $\begin{array}{c}\text { Statistical } \\
\text { significance }\end{array}$ \\
\hline CACS & $941(645-1238)$ & $182(0-405)$ & $<0.001$ \\
\hline AACS & $2773(2078-3470)$ & $431(0-945)$ & $<0.001$ \\
\hline Hematocrit (\%) & $33.6(32.8-34.5)$ & $40.9(38.5-43.3)$ & $<0.001$ \\
\hline Hemoglobin $(g / d L)$ & $11.1(10.8-11.4)$ & $14.0(13.2-14.8)$ & $<0.001$ \\
\hline Albumin $(g / d L)$ & $3.87(3.76-3.97)$ & $4.06(3.82-4.31)$ & 0.26 \\
\hline Creatinine $(\mu \mathrm{mol} / \mathrm{L})$ & NA & $77(66-88)$ & \\
\hline Total cholesterol $(\mathrm{mmol} / \mathrm{L})$ & $4.63(4.37-4.88)$ & $5.43(4.88-5.97)$ & 0.02 \\
\hline LDL cholesterol (mmol/L) & $2.61(2.39-2.83)$ & $3.17(2.71-3.64)$ & 0.04 \\
\hline $\mathrm{HDL}$ cholesterol $(\mathrm{mmol} / \mathrm{L})$ & $1.14(1.06-1.23)$ & $1.54(1.26-1.83)$ & 0.002 \\
\hline Triglycerides (mmol/L) & $1.94(1.67-2.22)$ & $1.44(0.72-2.15)$ & 0.02 \\
\hline Dyslipidemia (n /\%) & $75 / 72.1$ & $11 / 78.6$ & 0.85 \\
\hline Calcium (mmol/L) & $2.17(2.14-2.20)$ & $2.26(2.22-2.31)$ & 0.02 \\
\hline Phosphorous (mmol/L) & $1.88(1.74-2.03)$ & $1.04(0.95-1.13)$ & $<0.001$ \\
\hline Parathyroid hormone $(\mathrm{pg} / \mathrm{mL})$ & $409(313-506)$ & $50(40-61)$ & $<0.001$ \\
\hline $25(\mathrm{OH}) \mathrm{D}_{3}(\mathrm{ng} / \mathrm{mL})$ & $22.9(17.7-28.1)$ & $28.0(16.5-39.4)$ & 0.34 \\
\hline iFGF-23 (ng/mL) & $662.9(464.3-861.4)$ & $6.3(5.6-6.9)$ & $<0.001$ \\
\hline Osteocalcin (pmol/L) & $39.2(31.1-47.3)$ & $5.4(3.9-6.8)$ & $<0.001$ \\
\hline Osteopontin (ng/mL) & $103.2(93.5-112.8)$ & $27.8(23.8-31.8)$ & $<0.001$ \\
\hline Osteoprotegerin (pmol/L) & $14.7(12.0-17.3)$ & $5.0(3.8-6.1)$ & $<0.001$ \\
\hline Matrix GLA protein (nmol/L) & $11.1(10.2-11.9)$ & $13.6(12.2-14.9)$ & 0.01 \\
\hline Fetuin-A $(g / L)$ & $0.63(0.55-0.70)$ & $0.70(0.56-0.84)$ & 0.13 \\
\hline $\operatorname{CRP}(m g / L)$ & $12.6(9.2-16.1)$ & $1.2(0.8-1.6)$ & $<0.001$ \\
\hline IL-6 (pg/mL) & $7.3(5.4-9.1)$ & $2.6(1.3-3.8)$ & $<0.001$ \\
\hline TNF-a $(p g / m L)$ & $10.6(8.8-12.4)$ & $1.8(1.0-2.5)$ & $<0.001$ \\
\hline
\end{tabular}

NA - not available.

level $(<100 \mathrm{pg} / \mathrm{mL})$. Moreover, it was characterized by the lowest $25(\mathrm{OH}) \mathrm{D}_{3}$ and highest osteoprotegerin and CRP plasma levels.

The subgroup of patients with isolated AAC was younger (average of 12 years) than the subgroup with calcifications in both locations examined. This subgroup had also markedly higher plasma osteoprotegerin level (Tab. 3).

Serum phosphorous level and CaxP product were comparable in all HD study subgroups.

\section{Univariate correlations}

In patients with CAC, CACS was significantly associated with the HD vintage $(R=0.27, p=0.02)$, pack-years of smoking $(\mathrm{R}=0.37, \mathrm{p}=0.002)$, duration of hypertension therapy $(\mathrm{R}=0.28, \mathrm{p}=0.03)$, plasma levels of osteoprotegerin $(\mathrm{R}=0.32, \mathrm{p}=0.01)$ and MGP $(\mathrm{R}=0.305, \mathrm{p}=0.03)$. The severity of AAC was only related to age $(R=0.44$, $p$ $<0.001)$, plasma level of osteoprotegerin $(R=0.32, p=$ $0.003)$ and pack-years of smoking $(\mathrm{R}=0.36, \mathrm{p}=0.002)$.
There were significant inverse correlation between age and serum phosphorous level $(\mathrm{R}=-0.41, \mathrm{p}<0.001)$, CaxP product $(\mathrm{R}=-0.40, \mathrm{p}<0.001)$, PTH $(\mathrm{R}=-0.25$, $\mathrm{p}=0.01)$.

Moreover, there was a strong correlation between age and plasma osteoprotegerin level $(\mathrm{R}=0.60, \mathrm{p}<0.001)$ as well as IL-6 $(\mathrm{R}=0.28, \mathrm{p}=0.03)$.

\section{Multiple logistic regression analysis}

The multiple logistic regression analysis showed that only age (per year) $[\mathrm{OR}=1.13(1.07-1.18), \mathrm{p}<0.001]$ and time on HD therapy (per year) $[\mathrm{OR}=1.14(1.00-1.34)$, $\mathrm{p}=0.04]$ were independent risk factors favoring the occurrence of $\mathrm{CAC}$; while age $[\mathrm{OR}=1.20(1.11-1.30), \mathrm{p}<$ 0.001 ] was the only predictor of the AAC occurrence in HD patients.

\section{Discussion}

The results of our study demonstrate that AAC precedes the occurrence of CAC and reveal differences in factors favoring their development. Age and HD vintage was 
Table 3 Comparison of subgroups according localization of CAC and AAC (mean \& 95\% CI)

\begin{tabular}{|c|c|c|c|c|}
\hline & $\begin{array}{c}A A C \text { and } C A C \\
(N=76)\end{array}$ & $\begin{array}{c}\text { Isolated AAC } \\
(N=7)\end{array}$ & $\begin{array}{l}\text { No calcifications } \\
(N=19)\end{array}$ & ANOVA \\
\hline Age (years) & $60(57-63)$ & $48(33-63)$ & $31(27-34)$ & $<0.001$ \\
\hline Gender (male/female) & $41 / 35$ & $4 / 3$ & $10 / 9$ & 0.95 \\
\hline Smoking (n /\%) & $45 / 59.2$ & $5 / 71.4$ & $12 / 63.2$ & 0.67 \\
\hline Diabetes (n /\%) & $19 / 25.0$ & 0 & 0 & 0.001 \\
\hline Hypertension (n /\%) & $68 / 89.5$ & $6 / 85.7$ & $13 / 68.4$ & 0.02 \\
\hline Coronary artery disease (n /\%) & $33 / 42.3$ & $2 / 28.6$ & 0 & $<0.001$ \\
\hline Time on dialysis (months) & $45(32-59)$ & $22(10-34)$ & $36(15-56)$ & 0.48 \\
\hline $\mathrm{Kt} / \mathrm{N}$ & $1.30(1.25-1.35)$ & $1.24(0.93-1.54)$ & $1.31(1.20-1.42)$ & 0.75 \\
\hline Body mass index $\left(\mathrm{kg} / \mathrm{m}^{2}\right)$ & $25.2(24.3-26.2)$ & $23.0(18.9-27.2)$ & $23.1(20.9-25.3)$ & 0.09 \\
\hline Hemoglobin $(g / d L)$ & $11.1(10.7-11.4)$ & $11.4(10.4-12.5)$ & $11.0(10.2-11.8)$ & 0.80 \\
\hline Albumin $(g / d L)$ & $3.82(3.70-3.94)$ & $3.75(3.21-4.30)$ & $4.16(3.91-4.29)$ & 0.08 \\
\hline Total cholesterol (mmol/L) & $4.78(4.48-5.08)$ & $4.26(3.90-4.61)$ & $4.08(3.40-4.77)$ & 0.09 \\
\hline LDL cholesterol (mmol/L) & $2.75(2.50-3.01)$ & $2.44(1.91-2.98)$ & $2.19(1.63-2.75)$ & 0.12 \\
\hline $\mathrm{HDL}$ cholesterol (mmol/L) & $1.16(1.05-1.27)$ & $1.05(0.89-1.21)$ & $1.11(0.93-1.29)$ & 0.76 \\
\hline Triglycerides ( $\mathrm{mmol} / \mathrm{L})$ & $2.00(1.67-2.32)$ & $1.75(0.94-2.56)$ & $1.52(1.27-1.77)$ & 0.32 \\
\hline Dyslipidemia (n /\%) & $57 / 75.0$ & $3 / 42.9$ & $13 / 68.4$ & 0.37 \\
\hline Calcium (mmol/L) & $2.17(2.13-2.21)$ & $2.22(2.09-2.36)$ & $2.16(2.07-2.25)$ & 0.68 \\
\hline Phosphorous (mmol/L) & $1.78(1.62-1.94)$ & $1.94(1.27-2.61)$ & $2.16(1.78-2.54)$ & 0.12 \\
\hline Phosphorous >1.77 mmo/L (n /\%) & $40 / 52.6$ & $3 / 42.9$ & $14 / 73.7$ & 0.14 \\
\hline $\operatorname{CaxP}\left(\mathrm{mmol}^{2} / \mathrm{L}^{2}\right)$ & $3.84(3.49-4.18)$ & $4.31(2.26-5.77)$ & $4.64(3.84-5.43)$ & 0.12 \\
\hline PTH $(p g / m L)$ & $364(263-464)$ & $310(138-481)$ & $577(225-928)$ & 0.22 \\
\hline $\mathrm{PTH}<100 \mathrm{pg} / \mathrm{mL}$ (n /\%) & $20 / 25.6$ & 0 & $2 / 10.5$ & 0.06 \\
\hline $25(\mathrm{OH}) \mathrm{D}_{3}(\mathrm{ng} / \mathrm{mL})$ & $19.2(14.2-24.2)$ & $24.2(12.7-34.9)$ & $29.2(17.4-40.9)$ & 0.04 \\
\hline iFGF-23 (ng/mL) & $638.0(379.1-697.0)$ & $955.9(0-2524.2)$ & $698.8(363.5-1034.0)$ & 0.32 \\
\hline Osteocalcin (pmol/L) & $36.4(26.7-46.0)$ & $32.3(14.0-50.6)$ & $47.7(25.7-69.7)$ & 0.50 \\
\hline Osteopontin $(\mathrm{ng} / \mathrm{mL})$ & $98.1(86.8-109.4)$ & $124.4(104.9-143.9)$ & $98.5(80.3-116.7)$ & 0.31 \\
\hline Osteoprotegerin (pmol/L) & $17.5(14.1-20.9)$ & $12.0(3.7-20.3)$ & $6.4(4.3-8.5)$ & 0.003 \\
\hline Matrix GLA protein (nmol/L) & $11.5(10.5-12.5)$ & $9.1(4.0-14.2)$ & $9.8(7.9-11.8)$ & 0.13 \\
\hline Fetuin-A $(g / L)$ & $0.60(0.50-0.69)$ & $0.72(0.39-1.05)$ & $0.68(0.51-0.85)$ & 0.54 \\
\hline $\mathrm{CRP}(m g / L)$ & $12.9(9.3-16.6)$ & $10.6(7.2-18.1)$ & $8.2(2.4-14.1)$ & 0.03 \\
\hline$\| \mathrm{L}-6(p g / m L)$ & $7.5(5.3-9.6)$ & $6.8(4.2-8.4)$ & $8.1(1.0-15.3)$ & 0.68 \\
\hline TNF-a $(p g / m L)$ & $11.1(8.9-13.3)$ & $6.8(2.5-9.7)$ & $11.4(7.1-15.7)$ & 0.22 \\
\hline
\end{tabular}

equally $(\mathrm{OR}=1.13$ and 1.14) important for the occurrence of $\mathrm{CAC}$, while only age was a major $(\mathrm{OR}=1.20)$ predictor of the occurrence of AAC. Other traditional risk factors of atherosclerosis, correlated with $\mathrm{CAC}$ in our study, included diabetes and duration of hypertension therapy. All but one patients with obesity had CAC, but the limited number of obese patients precluded any statistical significance. We also failed to prove the association between dyslipidemia and $\mathrm{CAC}$ and $\mathrm{AAC}$, probably as lipid disorders in CKD certainly differs from those prior to HD therapy and reflects only the current status and overlapping treatment. We did not analyze the association between physical activity and calcification status as the group had highly heterogeneous age. Moreover, we did not analyze the long-term nutritional habits due to the lack of research tools.

The prevalence of CAC (73.1\%) is similar as previously reported - 65-90\% [9-12]. However, it was lower than reported by Goodman et al. in young adults with 2 -time longer dialysis vintage ( $7 \pm 6$ years) [13]. This pointing out the important influence of long-term vascular wall exposition on uremic milieu, later confirmed by Raggi et al. [10]. Additionally, in our study the frequency of calcifications increased 
with age especially during the third and fourth decade.

Among the most well-known and studied uremic abnormalities associated with development of vascular calcifications were mineral disturbances: hyperphosphatemia, high CaxP product, secondary hyperparathyroidism and adynamic bone disease. However, we did not find any difference in serum phosphorous and CaxP product, measured in a single sample, between patients with and without calcifications and the relationships between serum phosphorous and severity of calcifications in both localizations studied. This is not the only study that failed to demonstrate such a relation $[12,14,15]$. However, this observation does not exclude the driving force of phosphorous in the development of vascular calcifications as the subgroup with calcifications was significantly longer exposed to phosphorous disturbances (longer hemodialysis vintage). The lack of lower serum phosphorous concentration in significantly younger subgroup yet without vascular calcification can be explained by the more frequent non-adherence of younger patients to phosphorous binding drugs and diet recommendation [16]. Another possible explanation is time-dependent variation of serum phosphorous related to variability of dietary phosphate consumption, phosphate binder doses and duration of hemodialysis sessions. Recently Cianciolo et al. tried to overcome this problem calculating the period of exposure to phosphorous over $5.5 \mathrm{mg} / \mathrm{dl}$ and CaxP product over $55 \mathrm{mg}^{2} / \mathrm{dl}^{2}$ recorded during last 24 months [11]. In this study the independent contribution in multivariate regression was only shown for nondiabetic HD patients. This cited data and results of our study may suggest that during the last decade an important improvement of the mineral disturbances management was obtained, inter alia by dose reduction of calcium phosphorous binders and active vitamin D metabolites, introduction of sevelamer hydrochloride and cinacalcet, recently. The progress in secondary hyperparathyroidism management was associated with increased frequency of adynamic bone disease (ABD), and the risk for vascular calcification development [17]. In our study in subgroup with vascular calcification one of the four patients had low PTH level that characterize patients with $\mathrm{ABD}$.

Currently it is suggested that FGF-23 is a very sensitive marker of phosphorous disturbances. Additionally, an association between plasma FGF-23 levels and CACS or AAC were recently reported in studies assessed relatively small groups of hemodialysis patients with extremely high FGF-23 levels $[18,19]$. These interesting data were not confirmed by the results of lager study performed by Cianciolo et al. [11] and presented in our paper. It should be emphasized, that no FGF-23 vascular toxicity has been demonstrated yet.
There are several line of evidence showing that CAC are associated with systemic inflammation $[12,14,15]$, as the component of the malnutrition-inflammationatherosclerosis syndrome. Atherosclerosis frequently coexists with systemic inflammation especially in hemodialysis diabetic patients [20]. Experimental studies demonstrated that TNF- $\alpha$ in dose-dependent manner induce differentiation of VSMCs into osteoblast-like cells and stimulate mineral deposition [21]. We have also shown that patients with CAC and AAC had significantly higher serum CRP levels but not IL- 6 and TNF- $\alpha$. However, there was no correlation between circulating inflammatory markers levels and calcification scores. Timedependent high variability is a potential cause of the conflicting results.

The process of vascular calcifications has natural inhibitors, such as MGP, osteopontin, osteoprotegerin, fetuin-A and pyrophosphates [5]. However, in our study only plasma level of osteoprotegerin was significantly increased in patient with than without calcification and was related to their severity. The association between $\mathrm{CAC}$ and higher circulating osteoprotegerin concentration has been previously revealed by Barreto et al. in HD patients. The authors suggested that it represents an incomplete self-defensive response to the progression of atherosclerosis [22]. Similarly, it has also been shown that increased serum osteoprotegerin levels correlates with AACS [23]. Moreover, osteoprotegerin levels were associated with progression of CACS in HD patients [24]. The lack of independent contribution to the occurrence of CAC and AAC in our study suggest that circulating osteoprotegerin level is rather a marker of vascular pathology in HD patients.

In our study the assessment of AAC was performed with own method developed, similar to the evaluation performed in the CAC. While, in the earlier studies the assessment was based on the index coverage perimeter of the aortic wall [14]. We consider, the method used in our study is more precise. In consequence we detected higher prevalence of abdominal aorta calcifications than previously reported. Okuno et al. in abdominal X-ray imaging shown AAC in $56.6 \%$ of hemodialysis patients [25]. In the large multicenter CORD study including 933 adult hemodialysis patients [26], the prevalence of AAC was similar to those reported by us ( 81 vs. $79.9 \%)$. In this study the occurrence of AAC were related to age and dialysis vintage. While, we were unable to prove the effect of dialysis vintage on the occurrence and severity of AAC. On the other hand we showed the association between diabetes coexistence or smoking and the severity of calcifications, as was previously observed in the general population [27].

Our study shows not only some differences in factors associated with the occurrence of vascular calcification 
in elastic (abdominal aorta) and muscular (coronary) arteries but also demonstrate that AAC in HD patients develops usually in younger age than CAC does. This statement is also supported by the identification of a group of 7 patients with isolated AAC. This group of patients was by more than a decade younger, and additionally had remarkably shorter hemodialysis vintage than those with calcifications in both locations. This may suggest either the different effect of age or dialysis vintage on the development of vascular calcification in both locations. Though, the existence of positive correlation between hemodialysis vintage and CAC but not AAC suggest more deteriorative effect of uremic milieu on the pathogenesis of coronary vessel pathology. While, the development of AAC seems to be more dependent on traditional cardiovascular risk factors (i.e. age). This interesting observation necessitate further studies.

Our study has some limitations. The main one is the cross sectional study design and the heterogeneity of the study group in aspect of CKD causes, age and dialysis vintage. We cannot exclude that the strong impact of age does not mask weaker effects of mineral disturbances. Additionally, we did not assessed the uncarboxylated MGP fraction, but total MGP, that limits conclusions of their role for vascular calcification development. Moreover we did not analyzed the impact of prior to CKD diagnosis factors related to lifestyle, except smoking.

\section{Conclusion}

1. AAC precedes the occurrence of CAC in HD patients.

2. The exposition to uremic milieu and microinflammation has more deteriorative effect on the CAC than the AAC.

\section{Abbreviations}

CAC: Calcification of coronary arteries; ACC: Calcification of abdominal aorta; HD: Hemodialysis; VSMCs: Vascular smooth muscle cells; BMP-2: Bone matrix protein-2; MGP: Matrix Gla protein; CT: Computed tomography; MSCT: Multislice spiral computed tomography; CACS: Coronary arteries calcification score; AACS: Abdominal aorta calcification score; ABD: Adynamic bone disease.

\section{Competing interests}

The authors have declared that no competing interest exists.

\section{Authors' contributions}

PP - carried out CT analysis, participated in the design of the study and drafted the manuscript; $\mathrm{BC}$ - participated in the patients recruitment and drafted the manuscript; RF - participated in the data collecting and drafted the manuscript; KW - participated in the data collecting and drafted the manuscript; AK-Sz - participated in the data collecting and drafted the manuscript; MO-G - participated in the design of the study and drafted the manuscript; AW - participated in the design of the study and drafted the manuscript; JCh - participated in the design of the study, funds collecting, performed the statistical analysis and drafted the manuscript. All authors read and approved the final manuscript.

\section{Acknowledgements}

The study was supported by grant no. NN402 480539 from the National Science Centre.

\section{Author details}

'Department of Radiology, Medical University Hospital SPSK-M, Katowice, Poland. ${ }^{2}$ Department of Nephrology, Endocrinology and Metabolic Diseases, Medical University of Silesia, Katowice, Poland. ${ }^{3}$ Health Promotion and Obesity Management Unit, Department of Pathophysiology, Medical University of Silesia, Katowice, Poland. ${ }^{4}$ Pathophysiology Unit, Department of Pathophysiology, Medical University of Silesia, Katowice, Poland.

Received: 21 November 2012 Accepted: 8 January 2013

Published: 14 January 2013

\section{References}

1. Foley RN, Parfrey PS, Sarnak MJ: Epidemiology of cardiovascular disease in chronic renal disease. J Am Soc Nephrol 1998, 9(12 Suppl):S16-S23.

2. Lindner A, Charra B, Sherrard DJ, Scribner BH: Accelerated atherosclerosis in prolonged maintenance hemodialysis. N Engl J Med 1974, 290:697-701.

3. Shanahan CM, Cary NR, Metcalfe JC, Weissberg PL: High expression of genes for calcification-regulating proteins in human atherosclerotic plaques. J Clin Invest 1994, 93:2393-2402.

4. Tintut Y, Alfonso Z, Saini T, Radcliff K, Watson K, Boström K, Demer LL: Multilineage potential of cells from the artery wall. Circulation 2003, 108:2505-2510.

5. Mizobuchi M, Towler D, Slatopolsky E: Vascular calcification: the killer of patients with chronic kidney disease. J Am Soc Nephrol 2009, 20:1453-1464.

6. Stenvinkel P, Carrero JJ, Axelsson J, Lindholm B, Heimbürger O, Massy Z Emerging biomarkers for evaluating cardiovascular risk in the chronic kidney disease patient: how do new pieces fit into the uremic puzzle? J Am Soc Nephrol 2008, 3(2):505-521.

7. Shlipak MG, Fried LF, Cushman M, Manolio TA, Peterson D, Stehman-Breen C, Bleyer A, Newman A, Siscovick D, Psaty B: Cardiovascular mortality risk in chronic kidney disease: comparison of traditional and novel risk factors. JAMA 2005, 293(14):1737-1745.

8. Rumberger JA, Brundage BH, Rader DJ, Kondos G: Electron beam computed tomography calcium scanning: a review and guidelines for use in asymptomatic persons. Mayo Clin Proc 1999, 74:242-252.

9. Braun J, Oldendorf M, Moshage W, Heidler R, Zeitler E, Luft FC: Electron beam computed tomography in the evaluation of cardiac calcification in chronic dialysis patients. Am J Kidney Dis 1996, 27(3):394-401.

10. Raggi P, Boulay A, Chasan-Taber S, Amin N, Dillon M, Burke SK, Chertow GM: Cardiac calcification in adult hemodialysis patients. A link between endstage renal disease and cardiovascular disease? J Am Coll Cardiol 2002, 39(4):695-701

11. Cianciolo G, La Manna G, Donati G, Persici E, Dormi A, Cappuccilli ML, Corsini S, Fattori R, Russo V, Nastasi V, Coli L, Wratten M, Stefoni S: Coronary calcifications in end-stage renal disease patients: a new link between osteoprotegerin, diabetes and body mass index? Blood Purif 2010, 29(1):13-22

12. Kraśniak A, Drozdz M, Pasowicz M, Chmiel G, Michałek M, Szumilak D, Podolec P, Klimeczek P, Konieczyńska M, Wicher-Muniak E, Tracz W, Khoa TN, Souberbielle JC, Drueke TB, Sulowicz W: Factors involved in vascular calcification and atherosclerosis in maintenance haemodialysis patients. Nephrol Dial Transplant 2007, 22(2):515-521.

13. Goodman WG, Goldin J, Kuizon BD, Yoon C, Gales B, Sider D, Wang Y, Chung J, Emerick A, Greaser L, Elashoff RM, Salusky IB: Coronary-artery calcification in young adults with end-stage renal disease who are undergoing dialysis. N Engl J Med 2000, 342(20):1478-1483.

14. Nitta K, Akiba T, Suzuki K, Uchida K, Ogawa T, Majima K, Watanabe R, Aoki T, Nihei $\mathrm{H}$ : Assessment of coronary artery calcification in hemodialysis patients using multi-detector spiral CT scan. Hypertens Res 2004, 27(8):527-533

15. Ohtake T, Ishioka K, Honda K, Oka M, Maesato K, Mano T, Ikee R, Moriya H, Hidaka S, Kobayashi S: Impact of coronary artery calcification in hemodialysis patients: risk factors and associations with prognosis. Hemodial Int 2010, 14(2):218-225.

16. Karamanidou C, Clatworthy J, Weinman J, Horne R: A systematic review of the prevalence and determinants of nonadherence to phosphate 
binding medication in patients with end-stage renal disease. $B M C$ Nephrol 2008, 9:2.

17. London GM, Marty C, Marchais SJ, Guerin AP, Metivier F, de Vernejoul MC: Arterial calcifications and bone histomorphometry in end-stage renal disease. J Am Soc Nephrol 2004, 15(7):1943-1951.

18. Srivaths PR, Goldstein SL, Silverstein DM, Krishnamurthy R, Brewer ED: Elevated FGF 23 and phosphorus are associated with coronary calcification in hemodialysis patients. Pediatr Nephrol 2011, 26(6):945-951.

19. Jakuszewski P, Czerwieńska B, Chudek J, Wiecek A: Which components of malnutrition-inflammation-atherosclerosis syndrome are more common in haemodialysis patients with diabetic nephropathy? Nephrology (Carlton) 2009, 14(7):643-649.

20. Tintut Y, Patel J, Parhami F, Demer LL: Tumor necrosis factor-alpha promotes in vitro calcification of vascular cells via the cAMP pathway. Circulation 2000, 102(21):2636-2642.

21. Barreto DV, Barreto FC, Carvalho AB, Cuppari L, Cendoroglo M, Draibe SA, Moyses RM, Neves KR, Jorgetti V, Blair A, Guiberteau R, Fernandes Canziani ME: Coronary calcification in hemodialysis patients: the contribution of traditional and uremia-related risk factors. Kidney Int 2005, 67(4):1576-1582

22. Ozkok A, Caliskan Y, Sakaci T, Erten G, Karahan G, Ozel A, Unsal A, Yildiz A: Osteoprotegerin/RANKL axis and progression of coronary artery calcification in hemodialysis patients. Clin J Am Soc Nephrol 2012, 7(6):965-973.

23. Okuno S, Ishimura E, Kitatani K, Fujino Y, Kohno K, Maeno Y, Maekawa K, Yamakawa T, Imanishi Y, Inaba M, Nishizawa Y: Presence of abdominal aortic calcification is significantly associated with all-cause and cardiovascular mortality in maintenance hemodialysis patients. Am J Kidney Dis 2007, 49(3):417-425.

24. Honkanen E, Kauppila L, Wikström B, Rensma PL, Krzesinski JM, Aasarod K, Verbeke F, Jensen PB, Mattelaer P, Volck B, CORD study group: Abdominal aortic calcification in dialysis patients: results of the CORD study. Nephrol Dial Transplant 2008, 23(12):4009-4015.

25. Allison MA, Budoff MJ, Nasir K, Wong ND, Detrano R, Kronmal R, Takasu J, Criqui MH: Ethnic-specific risks for atherosclerotic calcification of the thoracic and abdominal aorta (from the multi-ethnic study of atherosclerosis). Am J Cardiol 2009, 104(6):812-817.

26. Nasrallah MM, El-Shehaby AR, Salem MM, Osman NA, El Sheikh E, Sharaf El Din UA: Fibroblast growth factor-23 (FGF-23) is independently correlated to aortic calcification in haemodialysis patients. Nephrol Dial Transplant 2010, 25(8):2679-2685.

27. Shiota J, Izumi N, Kasahara H, Tagawa H, Chiba T, Nihei H: Relationship between coronary and abdominal calcification score, serum osteoprotegerin (OPG), and serum tartrate-resistant acid phosphatase (TRACP) -5b in pre-dialysis CKD patients. Nihon Jinzo Gakkai Shi 2010, 52(8):1022-1028

doi:10.1186/1471-2369-14-10

Cite this article as: Pencak et al: Calcification of coronary arteries and abdominal aorta in relation to traditional and novel risk factors of atherosclerosis in hemodialysis patients. BMC Nephrology 2013 14:10.

\section{Submit your next manuscript to BioMed Central and take full advantage of:}

- Convenient online submission

- Thorough peer review

- No space constraints or color figure charges

- Immediate publication on acceptance

- Inclusion in PubMed, CAS, Scopus and Google Scholar

- Research which is freely available for redistribution

Submit your manuscript at www.biomedcentral.com/submit
( Biomed Central 